saturation occurred during the nights at that timea fact which again stressed the value of continuous records within the crop. Dr. C. L. Whittles (Auchincruive) urged the necessity for continuous records of such soil factors as $p \mathrm{H}$, water content, conductivity and oxidation-reduction potential.

\section{INDUSTRIAL DEVELOPMENT IN AUSTRALIA}

$\mathrm{T}$ HE paper 'Scientific Aspects of Australia's Industrial Development", which Mr. G. B. Gresford read before the Royal Society of Arts on January 16, naturally covers a good deal of ground in common with the annual reports of the Commonwealth's Council for Scientific and Industrial Research, though the account is rather more up to date and in a larger setting. Mr. Gresford referred particularly to the recent plans of the Australian wool industry, stimulated no doubt by competition from artificial fibres, for a large expansion of scientific research. Part of the large sum which the Australian Wool Board proposes to raise by increasing the levy on growers of wool would be spent by the Council for Scientific and Industrial Research on biological and textile research, and part would go towards economic research and publicity. Whether or not the opinion is justified that fundamental research will lead to the improvement of wool yield and quality, the cheapening of processing and the development of new and novel fabrics so that wool can more than hold its own, the link between science and the wool industry will become closer.

After a reference to research in connexion with grain crops such as wheat, and the significance of the results in the field of nutrition and developments in the manufacture of fertilizers and sulphuric acid, $\mathrm{Mr}$. Gresford mentioned particularly the part science has played in the development of the mining and metal industries. Investigations on flotation, and particularly the discovery of the collecting properties of potassium ethyl xanthate for the sulphide minerals, have led to the present high recoveries of lead and silver in the flotation sections of the mines. The work at the University of Melbourne on fundamental physical chemistry of the flotation process, which for ten years before the War was financed by a group of Australian mining companies, is now partly earried on by the Council for Scientific and Industrial Research. Work in new fields has suggested possible extensions of the flotation process to the concentra. tion of new minerals. Mr. Gresford also referred to the continuous lead refining process for dressed smelter bullion evolved by the staff of the Broken Hill Associated Smelters as a striking example of the application of physical chemistry to an industrial process.

The paper industry, and particularly the development of processes for a wide range of papers from eucalyptus woods by a chemical or mechanical method, provides a further example of the solution by scientific research of a problem deemed intractable, and which has now made the Australian industry almost entirely independent of imported materials. Referring to the universities as sources of supply of scientific personnel for industry, Mr. Gresford said that the demand at present greatly exceeds the supply, and if maintained it will involve a corresponding expansion of the universities. Plans have been made for a considerable expansion of Government research activities, but further expansion of research in industry is desirable. So far, scientific exploration has not revealed any sources of flow oil in Australia; attention has not been given to the synthetic production of liquid fuels from coal, although the brown coal deposits of Victoria are very similar to those used in Germany for this purpose. Organic chemical industry on a large scale has scarcely been started and the development of the chemurgic industries, utilization of agricultural wastes, alkaloids and essential oils are other fields awaiting the application of scientific methods in Australia.

\section{SYNTHESIS OF BIOTIN}

A SYNTHESIS of biotin by S. A. Harris, D. E. A Wolf, R. Mozingo, R. C. Anderson, G. E. Arth, N. R. Easton, D. Heyl, A. N. Wilson and K. Folkers, of the Research Laboratory of Merck and Co., Inc., has recently been described (J.Amer. Chem. Soc., 66, 1756 ; 1944).

The process involves several steps: $l$-cystine is reduced in liquid ammonia with sodium and coupled with chloroacetic acid to give $\beta$-(carboxymethylmercapto)-alanine, subsequent benzoylation and esterification of which yielded the dimethyl ester of N-benzoyl- $\beta$-(carboxymethylmercapto)-alanine. The diethyl ester was obtained by condensing thioglycolic ester with the ethyl ester of $\mathrm{N}$-benzoyl- $\beta$-chloroalanine, 'derived from $\mathrm{N}$-benzoylserine by esterifica. tion and chlorination with thionyl chloride. The dimethyl ester was treated with sodium methoxide in methanol to give the radium salt of 4-benzamido3-ketotetrahydro-2-thiophenecarboxylic acid methyl ester, racemization occurring during the reaction. The sodium salt was hydrolysed and decarboxylated in an aqueous acetic acid - hydrochloric acid solution to give 4-benzamido-3-ketotetrahydrothiophene. The valeric acid side-chain was introduced by means of an aldehyde prepared from glutaric acid. The acid was converted in turn to glutaric anhydride, glutaric acid monomethyl ester, $\gamma$-carboxymethoxybutyryl chloride, and finally to methyl $\gamma$-formylbutyrate by a Rosenmund reduction.

The aldehyde ester, condensed with the ketone, 4-benzamido-3-ketotetrahydrothiophene, with piperidine acetate as catalyst, yielded the methyl ester of 4 - benzamido - 3 - keto - $\Delta^{2, \delta}$ - tetrahydro - 2 - thiophenevaleric acid, which reacted with hydroxylamine hydrochloride in pyridine to yield the methyl ester of 4-benzamido-3-oximino- $\Delta^{2, \delta}$ - tetrahydro- 2 - thio phenevaleric acid, reduction of which by zine dust in an acetic acid - acetic anhydride mixture gave two compounds, one the methyl ester of 3-acetamido4 - benzamido - 4,5 - dihydro - 2 - thiophenevaleric acid. Hydrogenation of this over a palladium catalyst and fractional crystallization of the products gave two racemates of the methyl ester of 3-acetamido-4benzamidotetrahydro-2-thiophenevaleric acid. Each of these was hydrolysed with barium hydroxide, and subsequent treatment of the products with sulphuric acid gave the corresponding sulphates of the 3,4diaminotetrahydro-2-thiophenevaleric acids.

The acids, when treated with phosgene, yielded two racemates of hexahydro-2-oxo-1-thieno[3,4] imidazole-4-valeric acid, which will be called dl-biotin, and $d l$-allobiotin. The $d l$-biotin was resolved through its esters with $l$-mandelic acid to give biotin. 